\title{
THE HEALTHCARE DESIGN DILEMMA: PERILS OF A TECHNOLOGY- DRIVEN DESIGN PROCESS FOR MEDICAL PRODUCTS
}

\author{
H. Wilke ${ }^{1}$, P. Badke-Schaub ${ }^{2}$ and K. Thoring 1,2,凶 \\ ${ }^{1}$ Anhalt University of Applied Sciences, Germany, ${ }^{2}$ Delft University of Technology, The Netherlands \\ $\square$ katja@thoring.com
}

\begin{abstract}
This paper reports an embedded single case study from a globally operating manufacturer for digital healthcare products. Based on nine semi-structured interviews, document analysis, and a diary study among employees, we were able to gain insights on the daily business routines and interactions of the design team, the UX research team, and the product management department. The results revealed several unexpected insights that indicate a practical mismatch between user-centred design processes learned from the textbook and design practice in the healthcare sector that warrant further research.
\end{abstract}

Keywords: healthcare design, user-centred design, user experience, design process, industrial design

\section{Introduction}

Healthcare is a messy system of wicked problems that is hard to tackle (Jones, 2013, p. 21). Consequently, a user-centred design process with a focus on empathy building seems to be the appropriate strategy for designing healthcare products. The first author of this paper conducted an indepth case study at a globally operating manufacturer for analogue and digital healthcare products, in order to gain insights on the real-life design processes in the healthcare industry. The organization can be considered a market leader for a specific category of healthcare-related products to be used in hospitals and clinics. It has more than 12,000 employees worldwide and operates in more than 190 countries. For the purpose of this study we will keep the organization anonymous and refer to it as 'the organization'.

As a registered nurse and graduated designer, the first author of this paper has personal experience with the complex clinical situations and different stakeholders in healthcare as well as with the methods and innovation potentials of user-centred-design. Although healthcare is gaining more attention in design education (Noël and Frascara, 2016, p. 33) it is by far not yet, that only designers with clinical expertise are employed at medical product manufacturers. Due to the rapid evolvement of the design profession over the last decades towards developing a methodical, evidence-based, and holistic process, it is key for the designer with a user-centred design approach to conduct userresearch. Although this might be common sense among designers, it is not always a shared perception of other professions, which leads to a disregard of design research (Noël and Frascara, 2016, p. 32) and is restricting designers to the concept-phase of the development process. But since most designers are not familiar with professional healthcare, its stakeholders, and the complex clinical processes, it is 
essential for them to build up empathy with the users through extensive user-research, if they want to practice user-centred-design as they have learned it at design school. The resulting conflict and its consequences for designers as well as organizations are the focus of this study. Hence, this paper tries to answer the following research questions:

RQ1: What challenges are involved in the design processes of digital healthcare products, according to the case of a global healthcare manufacturing company?

RQ2: What implications and actionable advice can be derived for the design process of digital healthcare products?

\section{Theoretical background}

Designing for users in a medical context, for example patients or staff members, requires a deep understanding of their feelings, needs, and problems. The importance to gain empathy through user research and various tools is discussed, for example, by Sanders and Dandavate (1999) or Kouprie and Visser (2009). Jones (2013) elaborated on numerous problems that designers are nowadays facing when designing for healthcare. Among other issues, he emphasized that designers are being suspended from crucial steps of the healthcare design process (Jones, 2013, p. xviii). Moreover, he reports that designers have limited medical expertise (Jones, 2013, p. 290). As of today, only a few design educational programs offer a focus on healthcare (examples of medical design programs were found at TU Delft and University of Twente in the Netherlands, Umeå University in Sweden, and Muthesius University Kiel in Germany). Furthermore, Godbold et al. (2019) reported on various ethics-related challenges for design students when conducting user-centred projects in healthcare environments. Vice versa, also hospitals do not sufficiently establish their own design departments (Jones, 2013, p. 221). Experience-based codesign (EBCD) is an approach to improve healthcare services by combining user experience design with participatory design (Bate and Robert, 2007). According to Goodrich (2018), experience-based codesign improves the patient experience. However, Donetto et al. (2015) reported on difficulties of experience-based co-design processes between designers, hospital staff, and patients, mainly caused by power relationships between citizens and public services. Jones (2013) pointed out: "Design (of all disciplines) is not yet showing its impact in health services. For the most part, designers remain on the sidelines in institutions and practice. [...] Until we prove to be valuable contributing members of the care team, we risk being seen as specialists and even marginal players in the story of care." (Jones, 2013, p. xviii). Also, the implementation and evaluation of research prototypes in hospitals in order to gain feedback from patients and doctors, seems not to be common practice (Andersen, 2019).

These contradicting premises - the call for experience-based co-design (Bate and Robert, 2007) on the one hand, and the problems related to a lack of involvement, access, empathy, and medical expertise among healthcare designers (Jones, 2013) and on the other hand, indicate a practical mismatch that warrants further investigation. Anderson (2019) suggested two types of mismatch in the healthcare industry: (1) the gap between patients and clinicians that are caused by diverging experiences, and time resources of both stakeholders, and (2) the gap between designers and users (in this case not the patients but the medical staff). This paper focuses on the latter scenario. Although co-creation approaches seem to be the method of choice to bridge this gap between designers and users, such measures often end with a workshop, and developed prototypes rarely get implemented in real contexts in order to yield real feedback (Andersen, 2019; Hartswood et al., 2003).

While designers and the healthcare industry apparently struggle with building empathy for their users, global players such as Apple, Google, and Amazon are entering the healthcare market. Recently, Apple launched an extensive service for clinics to improve clinical communication, to simplify medical research, and to empower patients through information access (Apple Health, 2018). Similarly, Google is creating a new data infrastructure layer involving new data pipelines, pushing Google Cloud, building Google's own healthcare datasets for third parties, and developing AI-based healthcare systems (CBInsights, 2018a). Amazon is predestined to become the leading online-pharmacy, disrupt medical supply chains, and Medicare management with their logistics expertise and infrastructure (CBInsights, 2018b). By setting these kinds of standards, these global companies will most likely require traditional healthcare manufacturers and hospitals to become more competitive in the future. 


\section{Methodology}

In order to gain a comprehensive understanding of design processes in the healthcare sector, we followed the case study method suggested by Yin (2009). We conducted an embedded single case study (Yin, 2009, p. $38 \mathrm{ff}$.) that addressed several units within one single organization ('Type 2' case study). A single case was chosen because it was expected to serve as a critical case (Yin, 2009, p. 40) for investigating the contradicting assumptions outlined in our literature review. Moreover, different (embedded) units within the organization were studied: members from different departments, interactions between departments, the design process for several projects, information retrieval strategies, and user access. Through this embedded case study, we were hoping to gain rich insights on the design process in the healthcare sector that could be compared to the problems and requirements outlined in the literature.

Our data collection includes four different data sources: (1) Participatory observation: the first author of this paper spent five months as an intern working in the organization and hence was able to gain first-hand insights on work processes and design strategies. (2) Documents from a diary study among employees that provided insights on their information finding processes. (3) Interview data collected from nine semi-structured interviews with employees of the organization. (4) Documents of publicly available job postings that gave insights on the organization's requirements for the different professions involved in the design process. We followed Yin's principles for data collection by using several data sources that were later triangulated. The collected data (field notes, interview data, documents, and narratives) were stored in a database so that the inferred insights could be traced back to the evidences (Yin, 2009, p. $118 \mathrm{ff}$.). This procedure allowed us to achieve a comprehensive picture of the organization under investigation and to draw conclusions that will be discussed in the final section of this paper. In the following section, we describe each data collection method in detail, along with the results each study yielded.

\section{Case study results}

\subsection{Participatory observation}

During the five months internship in the design department of the organization, the first author was the responsible designer in two different project teams. Both projects had similarities regarding the process and interdisciplinary communication. They can also be seen as typical for the organization, based on the impressions and informal exchange with co-workers. There was no opportunity to observe the actual users (clinical staff) or getting exposed to the clinical field of use, due to limited resources in time and budget. The user research was solely conducted by the UX researchers and the product manager. Therefore, the only ways to build up empathy for the designers were (1) through the product-manager's communication of research findings, and (2) through self-initiated simulations of usage scenarios at the device itself. However, the briefings through the product managers were primarily focused on technical requirements. There was no material provided that might help designers make personal connections to the users' experiences, such as photos, quotes, or personas, as proposed by Kouprie and Visser (2009). A main part of the product manager's role was introduced by other designers as being the 'user's representative'. Therefore, any arising questions concerning user needs were primarily addressed to the product manager. The testing of design solutions with actual users was completely in the responsibility of the UX research department. This strict division of tasks in the design process was based on two paradigms: (1) To minimise bias: the proposed design solutions should not be tested and evaluated by the designers themselves. And (2) to assess effectiveness: the evaluation of design solutions should be executed by those who set the initial requirements. Due to these paradigms as well as limited resources, designers did not attend any user testing. Instead, the UX researchers reported the main findings back to the design team and pointed out, which aspects of the design solution required iterations.

\subsection{Diary studies}

Diary studies were conducted among employees in order to gain insights about the actual required medical knowledge for everyday design tasks in the organization. According to Hanington and Martin (2012, p. 66), "Diaries or journals are guiding artefacts that allow people to conveniently and 
expressively convey personal details about their daily life and events to design teams." Accordingly, we created a set of journals with pre-printed questions and issued them to ten participants from the organization's design team, the UX research team, and the product management team. We included a description of the topic of interests and instructions of usage. The diary study was conducted with in-situ logging (Flaherty, 2016) of arising medical-related questions and how those were answered. The ten participants were asked to carry the journal for one calendar week and to accomplish the following tasks: (1) to write down every medical/clinical-related question that arose during the project, and (2) to tick their chosen source of information in a given list, including an empty text field labelled 'other', if the used one was not listed. A detailing comment was kept optional. The participants provided an average of eight entries (with a range between three entries up to 27).

Through clustering of the responses, four different areas of knowledge seeking were identified: (A) the understanding of medical devices, (B) medical knowledge and terminology, (C) the understanding of users and context, and (D) the business side and medical market (Figure 1).

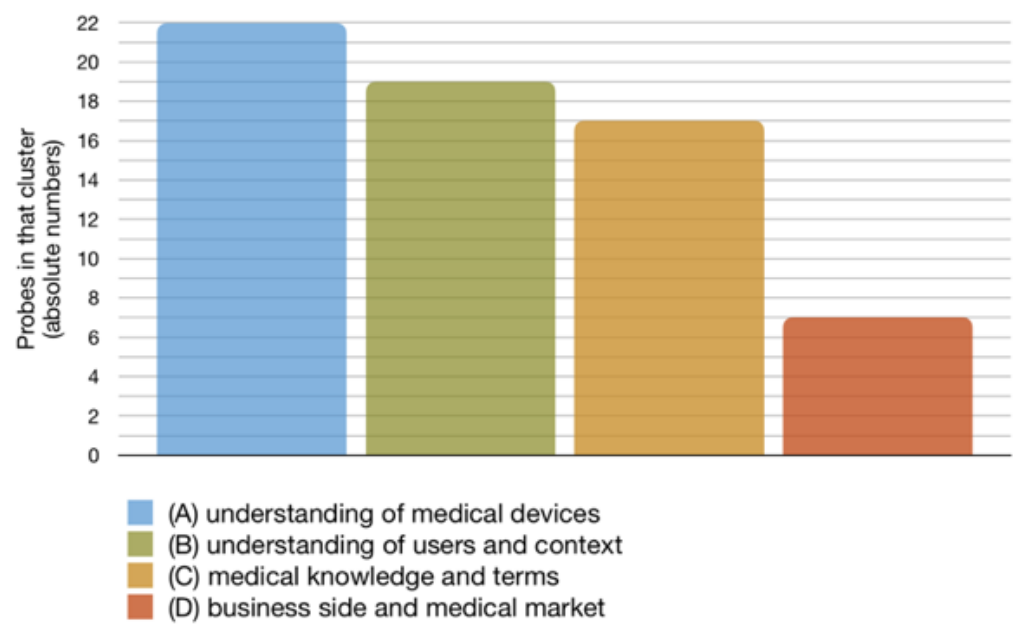

Figure 1. Clustering of diary entries into areas of knowledge seeking $(n=62$ entries in total)

The extensive use of informal sources ('Google' and 'asking colleagues'), for answering questions of category A and B was remarkable (Figure 2), whereas the variety of information sources for devicerelated questions was much broader. (Figure 3 ).

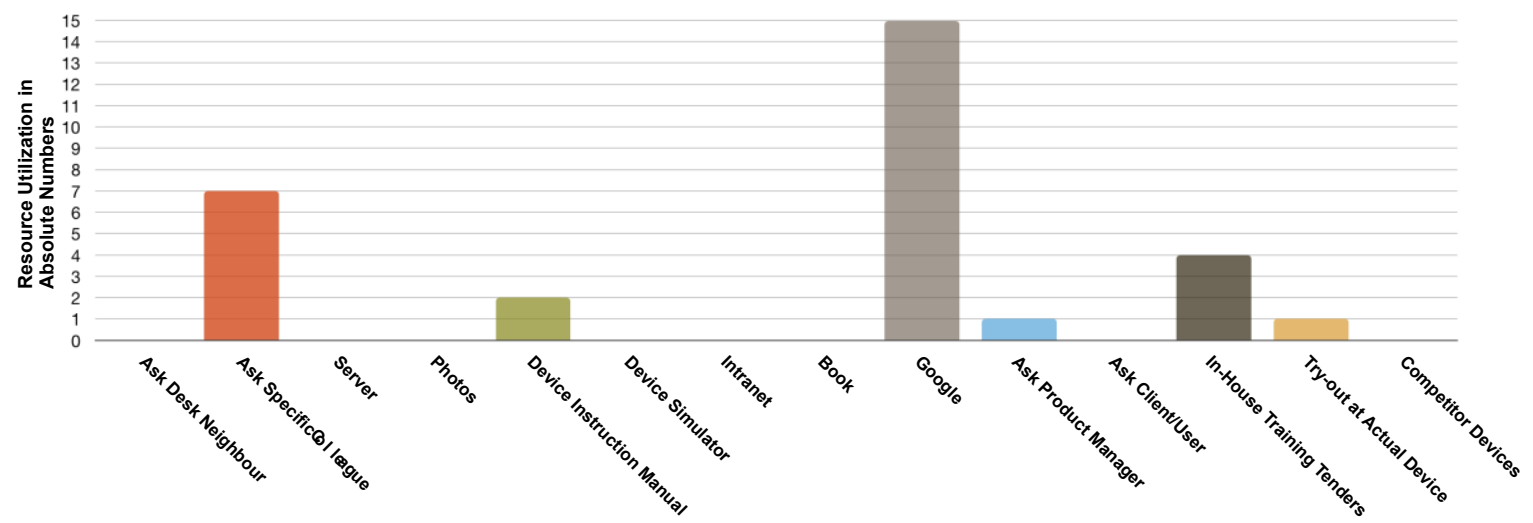

Figure 2. Utilisation of different sources of information for questions concerning 'medical knowledge and terms', based on a total of 30 entries from 10 diaries

These results already indicate a strong focus on devices, within the organization. Although there was an equal interest in understanding the medical background and the users (Figure 1), the organization seems to lack resources to answer those questions. It was also noticeable that when it comes to the understanding of users and use cases, the only information source for designers was the product manager. 


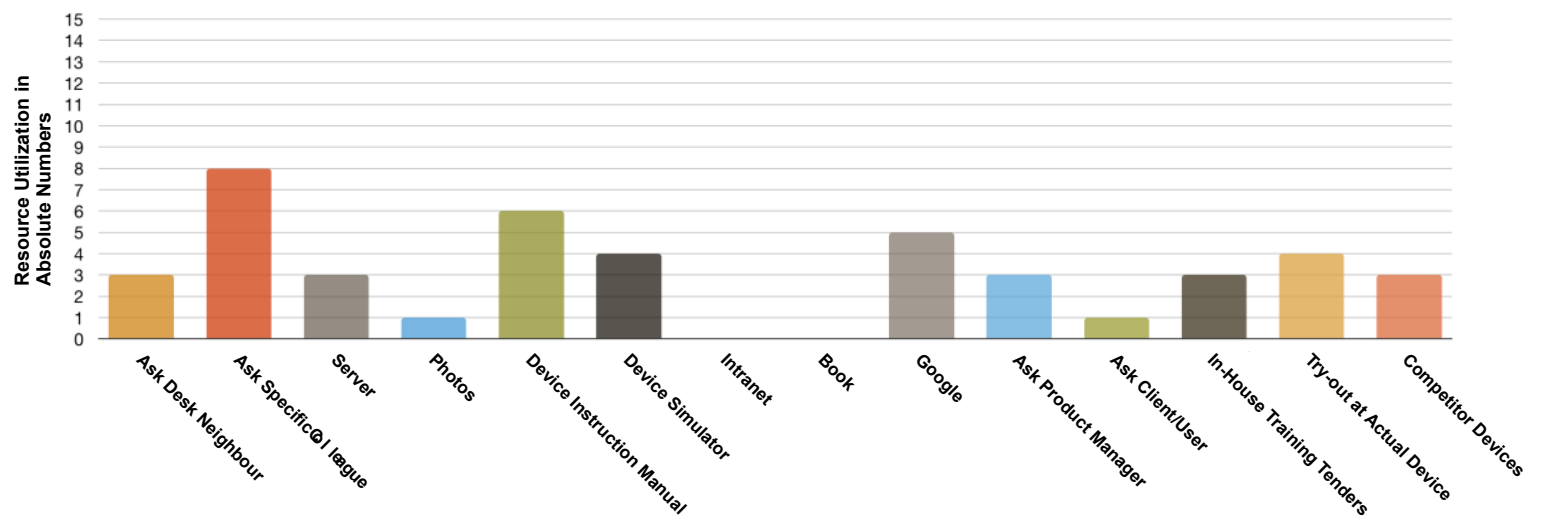

Figure 3. Utilisation of different sources of information for questions concerning the 'understanding of medical devices', based on a total of 44 entries from 10 diaries

\subsection{Interviews}

To verify and extend the results from the diary studies, nine semi-structured interviews were conducted. They also yielded insights on the participants' understanding of the design process used in the organization as well as their role within that process. The participants were selected to cover different departments and different levels of expertise in terms of years of experience. Five of the interviewees had previously participated in the diary studies and hence, it was possible to clarify emerging questions from the diary data. The interviews had an average duration of 34 minutes, each. They were audio recorded and transcribed for later analysis.

Table 1. Overview of interviews $(n=9$; designers $=6$; $U X$ researcher $=2$; product manager $=1)$

\begin{tabular}{ccc} 
Participant $\begin{array}{c}\text { years of working for the } \\
\text { organization }\end{array}$ & current department & $\begin{array}{c}\text { Previously worked } \\
\text { in healthcare }\end{array}$ \\
\hline
\end{tabular}

\begin{tabular}{lccc}
\hline \hline DES-1 & 5 & Design & no \\
\hline DES-2 & 1 & Design & no \\
\hline DES-3 & 7 & Design & no \\
\hline DES-4 & 0.5 & Design & no \\
\hline SI & 33 & Design / System Integration & yes \\
\hline UXR-1 & 4 & UX Research & no \\
\hline UXR-2 & 1 & UX Research & no \\
\hline ID & 7 & Industrial Design & no \\
\hline PM & 14 & Product Management & no \\
\hline
\end{tabular}

The first set of questions referred to the individual experience of mandatory training and introduction to the organization. The fact that there is a comprehensive mandatory training program for formal requirements, but it does not include medical knowledge, was mentioned repeatedly.

"There is a training program for new employees about the corporate philosophy and certain legal conditions. [...] But there were no basic medical trainings." (DES-4) [translated by authors]

Further statements among all interviewees also showed a desire for a comprehensive understanding of the medical backgrounds and clinical context to do their work in the best manner. Often accompanied by a general feeling of suffering from a chronic lack of time, because they feel forced to acquire the necessary knowledge through self-studies while parallel working on the actual project.

A lack of transparency about these circumstances, leading to a lack of exchange in resources, became clear by three employees independently reporting that they created a comprehensive index for themselves, to learn the medical abbreviations and terminology that were needed for their daily work. 
Furthermore, it was conspicuous that eight out of nine interviewees regarded it as the role of the product manager to be the 'user's-representative' and therefore primarily ask him any questions concerning the users. Only the interviewed product manager mentioned:

“...and that's what we forget here at [the organization]. People still think the product manager is the market and client's representative. [...] if you ask me, that is disastrous! I think that engineers and designers should also go [into hospitals] and understand how the client is thinking and acting." (PM) [translated by authors].

A dissonance in the understanding of the design discipline, its responsibilities and approach became noticeable in several statements, such as the one by DES-2:

"As I know it from my studies, design is actually involved from the very beginning. But in everyday work, design gets engaged just somewhere along the process. And then there are of course already pretty straight requests 'We want this and this and that..."”. (DES-2) [translated by authors].

Also, rich stories derived from the interviews turned out to be highly informative. For example, the following story of a simple redesign was told by DES-1. An existing product needed to get a modernising update without bigger technical changes. Therefore, the project's budget was low, but the small team and especially the young product manager went completely along with the user-centred-design process. All team members were involved from the very beginning and went into the hospital to observe the clinician's usage of the current product. They discovered several pain points and in close cooperation, they found suitable design solutions to improve the user experience. What started as a simple redesign project with little resources, turned out to generate a complete new USP for the whole product family. It was perceived as highly innovative by the users and helped the organization to stand out from competitors in this market field. This story can be seen as a best practice example for the user-centred design process, and its benefits in regard to design-driven innovation as well as its positive effect on employee satisfaction.

\subsection{Documentation of job advertisements}

Following artefact analysis according to Froschauer and Lueger (2016), current job vacancies of the organization for the design department, product management and UX research were analysed and compared. Table 2 outlines three job advertisements from the organization.

Table 2. Comparison of three job descriptions ("-" = not mentioned)

\begin{tabular}{llll} 
& Design & UX Research & Product Management \\
\hline \hline Medical knowledge & - & - & required \\
\hline $\begin{array}{l}\text { experience in clinical } \\
\text { practise }\end{array}$ & - & - & desirable \\
\hline process mentioned & user-centered-design & user-centered-design & - \\
\hline $\begin{array}{l}\text { description of particular } \\
\text { tasks \& responsibilities }\end{array}$ & $\begin{array}{l}\text { UX/UI-Design; } \\
\text { methodical user- } \\
\text { centred design }\end{array}$ & $\begin{array}{l}\text { planning, conducting, evaluating, } \\
\text { and presenting of user research } \\
\text { and user testing; derivation of } \\
\text { recommendations to improve UX }\end{array}$ & $\begin{array}{l}\text { product launch; } \\
\text { competitor analysis; } \\
\text { creation of product- } \\
\text { training material }\end{array}$ \\
\hline $\begin{array}{l}\text { collaborating } \\
\text { professions of the }\end{array}$ & - & - & - \\
department & & & \\
\hline
\end{tabular}

Looking only at the job description, designers might think that they will be participating in every phase of the design process. So, with this very early touchpoint for new employees comes already potential to build up wrong assumptions and therewith potential frustration in the actual working process later on. Furthermore, prior medical knowledge were not required or mentioned for the designers, but will also not be trained during the mandatory introduction training, although it will be needed for the actual design work. 


\section{Key findings}

After triangulating the insights from the different data sources, several key findings could be identified, which are summarized in the following subsections.

\subsection{Technology-driven design process}

The design process of the company was technology-driven instead of user-centred. In contrast, the designers described their own process as user-centred. The resulting dissonance is forcing designers to follow a process that they do not identify as their own and therefore causing feelings of stress and frustration. As Festinger pointed out "The existence of dissonance, being psychologically uncomfortable, will motivate the person to try to reduce the dissonance and achieve consonance." (Festinger, 1957, p. 3). To achieve consensus, designers had to work user-centred, although they were neither involved in the user-research phase, nor did they get a briefing which would allow them to build an emphatic connection to the user (as suggested by Kouprie and Visser, 2009). Because building such a connection is not seen as relevant within the technology-driven approach of the organization, designers needed to invest extra time and energy to understand their users to an extent which would allow them to fulfil their own aspiration of user-centred design. Figure 4 illustrates the dissonant processes, based on the company's own process diagram and an adapted process model from Kumar (2012).
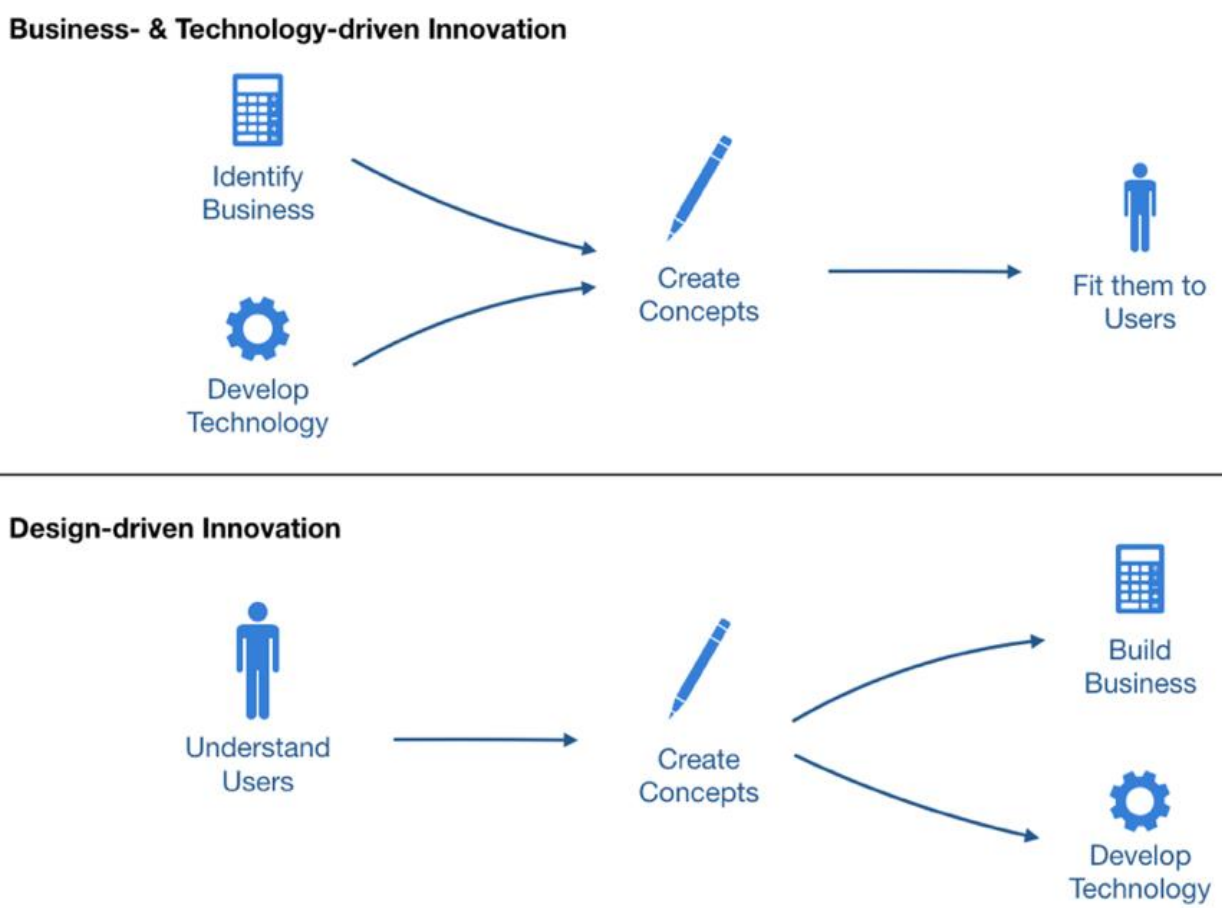

Figure 4. The innovation approach at the organization in comparison to the user-centred design process

\subsection{Lack of user access}

Moreover, the design process at the organization did not allow user access for the design team. Figure 5 shows an idealized new product development process that was in large part adhered to by the organization. The colour code illustrates the distribution of tasks within the design process in the studied organization. It becomes evident that the involvement of designers in the design process was limited to the ideation and prototyping steps. The two phases in which user access took place (research and testing), were reserved to UX researchers and product managers.

Designers had little to no contact to actual users (work shadowing was reserved to the UX research and product management teams). Therefore, designers had to rely on self-study or ask the product manager regarding the users. Figure 6 illustrates how user access, field work, and medical training were not available to the designers. 


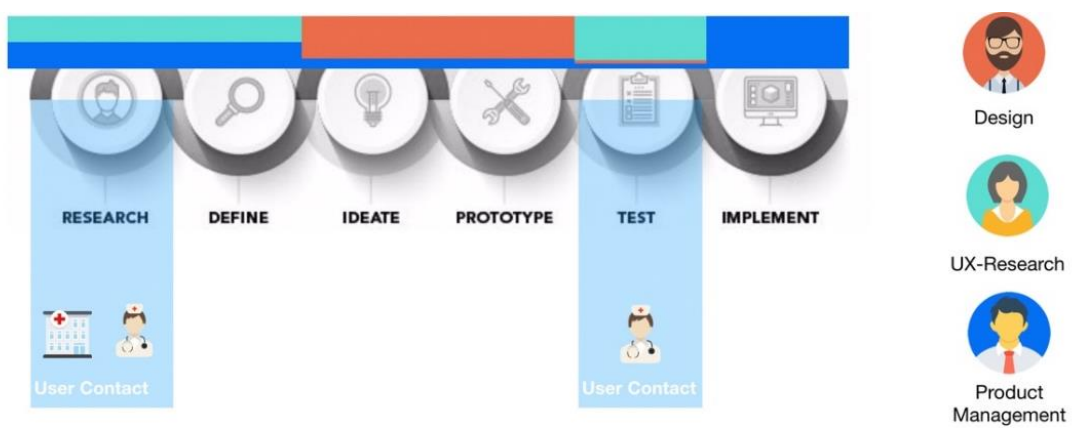

Figure 5. Observed development process at the studied institution; distribution of responsibilities

As stressed by Kouprie and Visser (2009), an empathic connection with the user can be seen as the foundation of user-centred-design. This was, however, not supported in the organization. This perspective is reflected in the following statement of DES-2:

\begin{abstract}
"I find it extremely important [to do field-research]. We also had the topic more often in our team meetings, that field-research and contact to the user is of great importance. Because I'm lacking of medical knowledge and somehow, I need to understand what is relevant to be able to prioritise, order and structure my work. And I simply cannot do that by myself with the knowledge I have. At this point I need more information, which I actually should get from the user; if he's conscious about it and otherwise through observation." (DES-2) [translated by author]
\end{abstract}

Also, the step in which product requirements were defined, was restricted to the UX research and the product management team.

\title{
5.3. Lack of medical expertise
}

According to the interviews, the design team members had little to no prior medical expertise and did not receive structured mandatory on-the-job trainings for medical knowledge, as the following quotes illustrate.

"There is a training program for new employees about the corporate philosophy and certain legal conditions. [...] But there were no basic medical trainings." (DES-4) [translated by authors]

"Basically, you have to prepare your own pool of knowledge through asking and googling. And probab ly every new employee is going through this process." (DES-

2) [translated by authors]
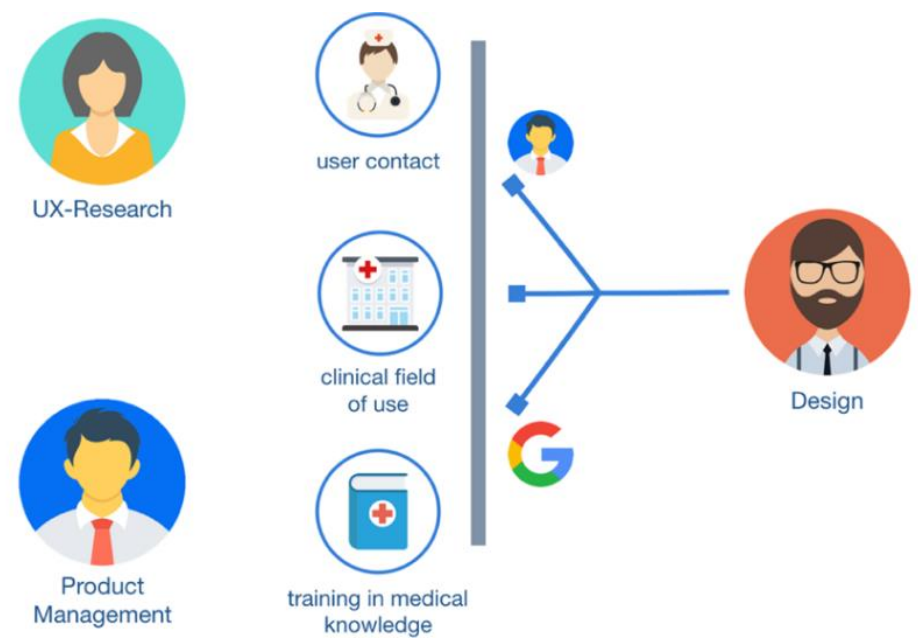

Figure 6. Designers were relying on Google self-study and reports from product manager for information on users, clinical context, and medical terms 
Nevertheless, basic medical knowledge is necessary for the design work in the organization. Especially since there is little or no possibility for designers to be in direct contact with the users.

Figure 6 illustrates the metaphorical 'barrier' between the designers and the users and the clinical field of use, as well as the lack of access to medical knowledge. The designers had to rely on the product manager for information on the users, and on Google for information on unknown medical terminology.

\section{Discussion}

The results of our study indicate a practical mismatch between user-centred design processes learned from the textbook example and design practice in the healthcare sector. The designers at the studied organization were not involved in user-research, defining product requirements, nor in the testing of ideas. Medical knowledge was not a requirement for employment.

The question arises, whether user-centred design methods, such as design thinking, have not yet reached publicly held corporations in the healthcare sector, such as the one we studied, or if design thinking might not be as effective as anticipated - at least not in technology-driven fields such as healthcare device manufacturing? Considering the growing competition from the big players like Apple or Google, as outlined earlier, the traditional players in the healthcare system might need to rethink their strategies. Our findings also revealed that designers struggled with the lack of user access and the lack of a medical training, which might result in reduced motivation.

In summary, the result from our study corroborate the challenges described by Jones (2013). Designers were not involved in the user research and testing phases of the design process, but rather limited to the concept phase. However, the developed prototypes were indeed tested in real contexts and later iterated - just not by the designers, which contradicts the problems described by Andersen (2019) and Hartswood et al. (2003). The problems identified in our study were more of an internal nature, where the designers were not involved in the user-research and the testing of the developed prototypes. This situation has not yet been described in detail in the analysed literature, to the best of our knowledge.

Based on the insights from the case study, we derive several actionable recommendations for healthcare design manufacturers, which also present manifold potentials for future work.

1. Involve designers formally in the user-research and testing phase, to let them build an empathic connection to the user via direct contact.

2. Improve interdisciplinary communication, for example by: sensitising the different professions for each other's' working methods and approaches by triggering discussions about the responsibilities to create a common sense (e.g. in workshops with card-sorting-methods); providing an in-house campaign informing about different departments and colleagues; providing shadowing-days where one follows and observes a colleague from another department for a day/week to get to know their actual tasks and daily business; and improving transparency in the distribution of responsibilities.

3. Develop and establish tools for remote research to support designers with the required user access, for example, remote video shadowing, heat-map analysis tools for the digital medical devices being in clinical use, and remote map-based observation of clinical users.

We argue that these suggested improvements would strengthen and potentially enhance the organization's strong market position through outcomes of design-driven innovation. Resolving the identified issues might not only result in better healthcare products, but also in a higher motivation of employed designers. Our suggestions add to the statements posed by Ciccone et al. (2019) who call for the consideration of the entire healthcare system and its stakeholders, a better understanding of people's behaviour, and improved data collection.

One limitation of our study is that it is analysing only one individual organization. However, the studied organization is a peculiar case (one of the world's market leaders for digital healthcare products) and we had the unique opportunity to gain deep access to this organization, which warrants our attempt to derive theoretical insight from this one case (Eisenhardt and Graebner, 2007). Nevertheless, our findings will need to be further investigated and validated through further studies in other organizations to verify whether the identified problems and our recommendations are transferable to other organizations and contexts. Moreover, future work will also include the 
development and testing of tools and applications for user research in the healthcare sector and to validate their effectiveness.

\section{Conclusions}

Based on an in-depth case study at a globally operating manufacturer for digital healthcare products, including participatory observation, diary studies, semi-structured interviews, and analysis of published job postings, we presented a comprehensive picture of the actual design processes in a healthcare manufacturing organization. The analysed design process contradicts the expected user-centred design approach. Instead, the process at the studied organization was technology-driven, designers were not involved in field research and user testing, and they had little to no prior medical expertise. These insights led to the development of three actionable recommendations for healthcare design manufacturers. The findings presented in this paper contribute to design practice by illustrating potentials for improving design processes in the healthcare sector.

\section{References}

Andersen, T.O. (2019), "Large-scale and long-term co-design of digital health", Interactions, Vol. 26 No. 5, pp. 74-77.

Apple Health (2018), "The Future of Healthcare is in your Hands", Apple Healthcare, available at: https://www.apple.com/healthcare/ (accessed 3 March 2019).

Bate, P. and Robert, G. (2007), Bringing User Experience to Healthcare Improvement: The Concepts, Methods and Practices of Experience-Based Design, Radcliffe Publishing.

CBInsights (2018a), How Google Plans To Use AI To Reinvent The \$3 Trillion US Healthcare Industry, available at: https://www.cbinsights.com/research/report/google-strategy-healthcare/ (accessed 3.3.2019).

CBInsights (2018b), Amazon In Healthcare: The E-Commerce Giant's Strategy For A \$3 Trillion Market, available at: https://www.cbinsights.com/research/report/amazon-transforming-healthcare/ (accessed 3.3. 2019).

Ciccone, N.W., Patou, F. and Maier, A.M. (2019), "Designing for Better Healthcare: A Systemic Approach Utilising Behavioural Theory, Technology and an Understanding of Healthcare Delivery Systems", International Conference on Engineering Design, Vol. 1 No. 1, pp. 937-946.

Donetto, S. et al. (2015), "Experience-based Co-design and Healthcare Improvement: Realizing Participatory Design in the Public Sector", The Design Journal, Vol. 18 No. 2, pp. 227-248.

Eisenhardt, K.M. and Graebner, M.E. (2007), "Theory Building from Cases: Opportunities and Challenges", Academy of Management Journal, Vol. 50 No. 1, pp. 25-32.

Festinger, L. (1957), A Theory of Cognitive Dissonance, Stanford Univ. Press, Stanford, CA.

Flaherty, K. (2016), "Diary studies: Understanding long-term user behavior and experiences", Nielsen Norman Group Articles.

Froschauer, U. and Lueger, M. (2016), Artefact Analysis in Organisational Research, p. 23.

Godbold, R., Lees, A. and Reay, S. (2019), "Ethical Challenges for Student Design Projects in Health Care Settings in New Zealand", International Journal of Art \& Design Education, Vol. 38 No. 1, pp. 182-192.

Goodrich, J. (2018), "Why experience-based co-design improves the patient experience", The Journal of Health Design, Vol. 3, No. 1 (2018)

Hanington, B.M. and Martin, B. (2012), Universal Methods of Design: 100 Ways to Research Complex Problems, Develop Innovative Ideas, and Design Effective Solutions, Mass, Rockport, Gloucester.

Hartswood, M.J. et al. (2003), "Working IT out in medical practice: IT systems design and development as corealisation", Methods of Information in Medicine, Vol. 42 No. 04, pp. 392-397.

Jones, P.H. (2013), Design for Care: Innovating Healthcare Experience, Rosenfeld Media, Brooklyn, N.Y.

Kouprie, M. and Visser, F.S. (2009), “A framework for empathy in design: stepping into and out of the user's life", Journal of Engineering Design, Vol. 20 No. 5, pp. 437-448.

Kumar, V. (2012), 101 Design Methods: A Structured Approach for Driving Innovation in Your Organization, Wiley, Hoboken, N.J.

Noël, G. and Frascara, J. (2016), Health and Design, Health Design Network.

Sanders, E. and Dandavate, U. (1999), "Design for experiencing: new tools", First International Conference on Design and Emotion, TU Delft.

Yin, R.K. (2009), Case Study Research, 4th ed., Sage, Newbury Park. 